jumping machinery; but in the matter of house-fittings there had been great progress, especially in the detection and prevention of waste of water. With respect to gas as a distributed illuminant, considerable improvements had lately been made, due to a greater liberality on the part of lighting-authorities, and to the use of mulliple burners in street-lanterns, by which a greater amoint of light was obtained from the same volume of gas. The regenerative gas-burners, and $n$ her modes, promised largely to increase the candle-power per culsic foot of gas burnt.

In conclusion, the President stated that, during his term of office, he would do all that lay in his power, as he had done in the past, to uphold the honour, the dignity, and the usefulness of the Institution; and in these efforts he felt satisfied that all the members would cheerfully and glatly assist.

\section{HOW THOUGHT PRESENTS ITSELF AMONG THE PHENOMENA OF NATURE'}

FVERY phenomenon which a human being can perceive may be traced by cientific investigation to motions going on in the world around him. This is obvious to every scientific man in regard to such phenomena as those of colour and sound, and these simpler cases were first adduced by the lecturer. He then pointed out that the statement is also true of all other material phenomena, and be specially dwelt on the phenomena investigated in the science of mechanics, showing that all the quantities treated of in that science, such as force and mass, prove, when the investigation is pashed far cnough, to be expressible in terms of mere motion. He also showed that the prevalent conviction that motion cannot exist unless there is some "thing" to move will not stand examination. It proves to be a fallacious conviction traceable to the limited character of the experience of motions which we and our ancestry from the first dawn of organised thought on the earth have had within reach of our senses. This conviction accordingly has no authority with respect to molecular motions and to some others that have been brought to light by scientific study. He also showed that the "thing" which in common experience moves, proves in every case to be nothing else than these underlying molecular motions, the transference of which from place to place is the only kind of motion which common experience can reach, when unassi ted by science.

The intermediale steps batween the world external to our bulies and the brain which take place in our organs of sense and nerves can also be ascertained to be motions. And finally, a change consisting of motions takes place in the brain itself, whereupon we become conscious of thought: i.e. a change occurs within the brain which would be appreciated as motions by a bystander who coukd search into our brains while we are thinking, and could witness what is going on there, while all the time the change that we experience is thought. It must be borne in mind that our brain is a part of the external world to the bystander whom we have supposed to be observing what is going on in it. It thws appears that every phenomenon of the external world is reducible to moti ins and their modifications, while all that is within the mind is thought.

Now this m tion to which all other material phenomena are reduced, this motion as it cxists in nature, must be distinguished from man's conception of motion, which, after all, is one of his thoughts - a very complex one, no doubt, but not pirt of the external world. This particular conception in our minds is on remote effect of the motion as it exists outside us, and what we really know of that external cause is that it is a cause which does unfailingly produce this effect if the intermediate appliances of our senses and nerves are also present. Motion, the canse, must no doubt stand in absolutely rigorous relations to its effect, viz. oar conception of motion; but it need not be liks: its effect, the presumption being quite the other way. The lecturer pointed out that, under these circumstances, the simplest and so far the most probable, hypothesis that can be advanced is the monistic hypothesis that this unknown cause is itself thought; and ho pointed out that it is no objecti in to this view that we are unconscions of all the thought here supposed, for this is only to say that it is external to that particular group of interlacing and oryanised thoughts which we call our own mind, just as the thoughts of the many millions of our fellow-men and of all other animals are external to our little group.

6), by G. Johnstone Stoney, M.A., D.Sc, F. S c inening discourse (February
The lecturer accordingly recommended the following hypothesis: (I) as consistent with everything we know, (2) as the simplest hypothesis, (3) as an hypothesis which dispels all the difficulties that encumber the dualistic supposition that there are two kinds of existence, viz. the hypothesis that if a bystander were armed with adequatc appliances to ascertain what is going on in our brain while we are thin'sing, then what we should experience to be thought is itself the remote cause with several intermediate causes of that change within the observer's brain which determines his having that complex thought which he would call perceiving some of the motions in our brain - in short, that whit he appreciates as motion we experience to be thought.

If this view be correct, it will follow that the thoughts of which we are conscious are but a small part of the thought going on evea in nur own brain, and which would be seen by a beholder as motions, the rest being unconscions cerebration and as much outside our consciousness as are the thoughts of other people. We are led also to the conclusion that the thought which is going on in the brains of all the animals that exist is but the "small dust of the balince" compared with what is going on throughout the rest of the mighty univere.

\section{SCIENTIFIC SERIALS}

Tue American Fournal of Scienc, February. - Obituary notice of Benjamin Silliman, son of Benjamin Silliman, the founder of that Foumal, and long one of its editors, who died in his sixtyninth year at New IIaven, Connecticul, on January 14, 1885.The organisation and plan of the United States Geological Survey, with a map, by J. W. Powell. The organisation, as at present established, comprises : (I) an a tronomic and computing division, the officers of which are engaged in determining the geographic coördinates of certain primary points; (2) a triangulation corps cngrged in extending a system of triangulation over various portions of the country from measured base-lines; (3) a topographic corps, organised into twenty-seven parties scattered over various portions of the United S'ates. - Memorial of the late distinguished butanist, George Bentham, by Asa Gray.Palacontological notes on the material from the St. John group of New Brunswick contained in the Hartt Collection at Cornell University, by Charles $\mathrm{D}$. Wal ott. - On the rotation of the cquipotential lines of an electric current by magnetic action, by E. H. Hall. The results are given of experiments made during the month of August, 1883, and at intervals since in the physical laboratory of Harvard College, the substances examined being chicfy copper, zinc, certain of their alloys, iron, and steel.-On the use of the term "Esker, or Kam drift," by J. Henry Kinahan. Both terms are traced to a Keltic source, căm, short (not kàme, long, as wrongly pronounced in England and the Lowlands), meaning, in Irish, crooked or winding, as in the river Cam, while Eskir or Eiscir denotes a small but welldefinel ridge.- On the cause of mild polar climates, by James Croll. In this third paper the author discusses the climate of the Tertiary period in so far as affected by eccentricity, the evidence of climatic alterations and of glaciation during the same periol. - Notice of the remarkable marine fanna occupying the outer banks of the southern coast of New England, by A. W, Verrill.--Note on a fossil coal plant found at the graphite deposit in mica chist at Worcester, Massazchusetts, by Joseph H. Ferry.-The test-well in the Carboniferous formation at Brownville, Nebraska, by Prof. L. E. Hicks,-Review of Hill's supplement to Delaunay's "Lunar Theory," by John N. Stockwell.

THE Fournal of Botany for February contains a plate of several new or rare species of Desmid to illustrate one of a series of papers on these organisus, by Mr. W. Joshua. It contains also the anmual list of new flowering plants published in periodicals in Britain in 1884. Most of the other articles are descriptive.

Bulletin de l'Acalemit lisyale de Belgique, December, 1884. - On the microscopic intrusions of sagenite in the titaniferous oolitic hematite of the clay-slates, by A. F. Renard.-On the external branchial apertures of the Ascidians, and on the formation of the intestine in Phallusia s abrödes (new species), by Edouard Van Beneden and Charles Julin,-On certain new animal organisms forming a local fauna peculiar to the neighbourhood of Thornton Bank, by Ed. Van Beneden,-On the presence of Nipharcus puteanus, Sch., in the Liége district, by Ed. Van Beneden.-Action of high pressure on the vitality of 
yeast, and on the phenomena of fermentation, by A. Certes and D. Cochin.-On the presence of duodenal anchylostoma in some Belgian hospitals, by $\mathrm{Ch}$. Fisket. - On the presence of a coxal gland in Galcodes araneoides, by J. MacLeod.-Note on G. Edon's work on the Carmen Arvale, by Alph. Le Roy.-Some details on Wissant and its identification with the Portus Iccius of the Romans, by Alph. Wauter.-On the apparent enlargement of the orbs of the sun and moon, by Paul Stroobant.-On a new Balensptera rostrata in the Mediterranean, by J. Van Beneden.-Discourse on geological chronology, by Ed. Dupont. -On the chief cause of cyclones and tropical calms, by M. Folie.

Bulleín de l'Académie des Sciences de St. Pítersbourg, tome xxix. No. 4- - On the applications of the interpolation method proposed by M. W. Tchebychef, by $O$. Backlund (in German). The fine method of the Russian mathematician is shown to be easily represented in a simple scheme, appropriate to calculations, and the author applies it to three examples, one of which is the calculation of Hasselberg's spectral observations. Ho shows that, with regard to the easiness and simplicity of calculations, the Tchebychef method leaves nothing to desire, while its.results are as reliable as those obtained by the much more tedious method of least squares. Two other examples, one for the declinations as taken from the Cape Catalogue, and compared with those measured at Pulkova, and another for interpo'ating Pulkova double-star observations, give the same satisfactory results. As known, Tchebychef's method permits also to proceed without making any previous hypothesis as to the degree of the interpolation formula. On the whole, when a considerable number of data is given, and the least squares' method becomes especially tedious, Tchebycheff's method gives excellent results. - The elements and the ephemerides of the Encke comet for its appearance in 1884-85, by O. Backlund. The ephemerides are given from November 7, I884, to May 6, 1885. - Demontration of several theorems relative to the numerical function $E(x)$, by V. Bouniakovsky (in French).-Contributions to the Ornis of the Ternate Island, by Th. Pleske (in German). The birds brought from the above island by Dr. Fischer are determined with the help of Salvadori's "Ornithologia della Papuasia," \&c. There are eighty-five species described. -Remarks on the Elapomo phus genus of Calamaride serpents, by A. Strauch (in German) Having received an herpetologic collection from Brazil, from Dr. Thering, Prof. Strauch found in it a new species of Elafomorphus, which he describes under the name of $E$. Theringii, and he accompanies the description by a thorough critical revision of all known species of the same genus. The paper is thus a systematic monograph of the genus, which contains now eighteen species.

THE Belyique horticole for July to September, I884, contains a retranslation of Prof. Jacobsthal's essay on " The Evolution of Vegeta'le Forms in Decorative Art," and M. Guirand's on the gardens of the Mediterranean coast, which have already appeared in our columns. We have also other asticles of interest taken from other journals, and the usual descriptions and admirable coloured plates of new plants.

\section{SOCIETIES AND ACADEMIES} LONDON

Royal Society, February I2.- " Note on the Condensation of Gases at the Surface of Glass." (Preliminary.) By J. T. Bottomley, M.A, F.R.S.E. Communicated by Prof. Sir William Thomson, F.R.S.

It is well known to those who have endeavoured to obtain, in glass vessels, the very perfect vacuums first sought after and obtained by Crookes, and producible by the mercurial pumps, that the operation is much assisted by heating the glass vessels to be exhausted, and even the tubes of the pump, to a high temperature. The difficulty of removing the film of air and moisture adhering to glass tubes is also well known to makers of barometers and thermometers.

When the Sprengel pump is used for producing a vacuum, and when a tolerably good vacuum has been produced, so that the barometric gauge indicates a presence of one millimetre or half a millimetre of mercury, the drops of mercury falling in the tube of the Sprengel give rise to a loud metallic hammering sound; and they fall with such unbroken sharpness that those who use this form of pump are often troubled by the "falltubes "splitting longitudinally through a length of several inches -a phenomenon in itsclf very remarkable, considering the strength of the tubes and the smallness of the mercurial drops.
If, while this hammering is going on, the glass vessel which is being exhausted and the leading tubes of the Sprengel pump be heated by passing the flame of a spirit-Iamp or of a Bunsen burner over them, the hammering immediately ceases, and on looking closely at the fall-tubes it is seen that they are carrying down air which the heat has liberated from the glass walls of the apparatus. The ordinary barometer-gauge is scarcely sensitive enough to show an increase of pressure, but the McLeod gauge readily shows it.

There is another well-known phenomenon connected with the condensation of gases and vapours on the surface of glass : viz. the condensation of a watery film over the glass of electric apparatus, in virtue of which, at temperatures considerably above the dew point, the glass supports are not insulators of electricity. This film of moisture is removed by exposing the glass stcms to heat, or to an artificially dried atmosphere. Some years ago, at the wish of Sir William Thomson, I endeavoured to weigh this film of moisture, but was absolutely unsuccessful. The film must be of extreme tenuity. Prof. Quincke has, however, made important researches on the "distance of capillary action" and on some of the properties of these very thin films. His results are given in two papers: Poggendorff's Annalen, I08, p. 326, I859; and Wiedemann's Annalen, vol. ii. 1877, p. 145 . He finds their thickness to be comparable with $5 \times 10^{-5} \mathrm{~cm}$.

With the view of measuring the quantity of gas condensed upon a given surface of glass, 1 caused to be prepared in August last a large quantity of fine glass thread. Some of this was of flint glass rod or cane, which was softened in the blowpipe flame, and drawn out on to a wheel. The remainder was of flint glass tubes, drawn out in a similar way. The spun glass was carefully parcelled up in paper and put aside till I should be ready to use it.

On January 3 I put a quantity of the non-tubular glass fibre into a glass tube $2 \mathrm{~cm}$. in diameter and $12 \mathrm{~cm}$. long, and attached it by a glass saling to a five-fall Gimingham Sprengel pump. The pump, which was in excellent order, was then worked rapidly till I had produced a very good vacuum, which by the McLcod gauge gave me an indication of $0: 3 \mathbf{M}$ pressure. The pump was then left for about an hour, and at the end of that time, passing one more bottle full of mercury through the pump, I ascertained that the vacuum had not sensibly deteriorated, the McLeod gattge giving identically the same reading as before. This exhaustion was performed without the application of any unusual heat to the tube containing the glass fibres. The temperature of the room was about $56^{\circ} \mathrm{F}$.

I now raised the mercury to the upper level and allowed it to flow through the pump, and the drops fell with the well-known lout hammering noise. While this was going on I applied a Bunsen burner to the tube containing the spun glass. In a few seconds the hammering of the mercury ceased, and on applying the test of the McLeod gauge the pressure within the pump was found to have risen largely. I did not, however, obtain a measurement with the gauge corresponding to the maximum pressure of the gas driven off, or to any particular state.

I now proceeded to pump out all the gas I could, working the pump and heating the tube containing the glass fibres strongly. The heating was carried on from time to time till the tube, which was of German glass, showed signs of softening and of falling in ; and the glass fibres were likewise, some of them, slightly softened and bent.

The pump was worked for over an hour, the heating being applied, and the gas, which was easily seen being carricd down, was collected in a tube made for the purpose, which was fitted on over the upturned ends of the five fall-tubes. At the end of this time the vacuum was again fairly good, though not so good as it was. before the heating commenced. The McLeod gauge indicated $\mathrm{I} \cdot \mathbf{2} \mathrm{M}$. It was seen that very little more air was being carried down, and I did not wish to push the vacuum farther than, or quite so far as, the vacuum which had been obtained before the liberation by heat of the condensed gas.

The collecting tube was now removed, and the gas obtained was measured and analysed, so far as it was possible to analyse a quantity so small.

The total amount of gas collected was calculated to be, at $15^{\circ} \mathrm{C}$. and a pressure of $760 \mathrm{~mm}$., 0.45 of a cubic centimetre. To this a small quantity of strong solution of caustic potash was added, and time was given for absorption. A small quantity of pyrogallic acid was next added, and the further absorption observed. The residue was so small that I could do nothing farther.

I M standing for one-millionth of an atmo. 